\section{Effect of Trust between the Time Pressure and Complexity in Judging and Decision-Making in Auditing}

\author{
Efeito da Confiança entre a Pressão de Tempo e Complexidade no \\ Julgamento e Tomada de Decisão em Auditoria
}

\section{ABSTRACT}

Objective: the study aimed to assess the moderating effect of confidence in the joint influence of time pressure and complexity in judgment and decision-making (JDM) in auditing. The behavioral decision theory (BDT) was used from the perspective of the anchoring heuristic. Methods: as a method, the $2 \times 2 \times 2$ experiment was used with a final sample of 126 independent auditors. For analysis, the t-test and multiple linear regressions were used. Results: the findings allow us to infer that factors such as trust, time pressure, and complexity, individually and jointly, influence JDM. The study showed that trust moderates the joint influence of time pressure and complexity on JDM. Time pressure and task complexity negatively influence JDM, but when including trust as a moderating factor, the effect of time pressure and complexity is mitigated, reducing the auditor's difficulties and uncertainties in JDM. Conclusion: the study contributes to BDT, moving academic research toward understanding the interrelationships between personal, environmental, and task factors. It also contributes by presenting evidence that there is a need for considering and observing the effects generated by the factors altogether, in order to contribute to improving the quality of the audit.

Keywords: judgment and decision-making in auditing; trust; time pressure; task complexity; anchoring heuristics.

\footnotetext{
* Corresponding Author.

1. Universidade Federal de Mato Grosso do Sul, Programa de Pós-Graduação em Ciências Contábeis, Campo Grande, MS, Brazil.

2. Universidade Regional de Blumenau, Programa de Pós-Graduação em Ciências Contábeis, Blumenau SC, Brazil.

3. Universidade do Estado de Santa Catarina, Curso de Graduação em Ciências Contábeis, Ibirama, SC Brazil.

Cite as: Santos, C. A., \& Cunha, P. R. (2021). Effect of trust between the time pressure and complexity in judging and decision-making in auditing. Revista de Administração Contemporânea, 25(5), e200037. https://doi.org/10.1590/1982-7849rac2021200037.en
}

\# of invited reviewers until the decision:

\begin{tabular}{|c|c|c|c|c|c|c|c|c|c|}
\hline & 1 & 2 & 3 & 4 & 5 & 6 & 7 & 8 & 9 \\
\hline $1^{\text {st }}$ round & (x) & $\stackrel{8}{6}$ & (x) & 9 & (x) & $\stackrel{9}{2}$ & (x) & & \\
\hline $2^{\text {nd }}$ round & 2 & & & & & & & & \\
\hline $3^{\text {rd }}$ round & 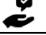 & & & & & & & & \\
\hline
\end{tabular}

Objetivo: o estudo objetivou avaliar o efeito moderador da confiança na influência conjunta da pressão de tempo e complexidade no julgamento e tomada de decisão (JTD) em auditoria. Utilizou-se a teoria da decisão comportamental (TDC) sob a ótica da heurística da ancoragem. Métodos: como método foi utilizado o experimento $2 \times 2 \times 2$, com amostra final de 126 auditores independentes. Para análise foram utilizados o teste t e a regressão linear múltipla. Resultados: os achados permitem inferir que os fatores confiança, pressão de tempo e complexidade, de forma individual e conjunta, influenciam no JTD. O estudo mostrou que a confiança modera a influência conjunta da pressão de tempo e complexidade no JTD. A pressão de tempo e a complexidade da tarefa influenciam negativamente o JTD, mas ao incluir a confiança como fator moderador, o efeito da pressão de tempo e da complexidade é atenuado, diminuindo as dificuldades e incertezas do auditor no JTD. Conclusáo: o estudo contribui para a TDC, na perspectiva de que investigações caminhem para compreender as inter-relaçôes entre os fatores pessoal, ambiental e de tarefa. Contribui também ao apresentar indícios de que há uma necessidade de que os efeitos gerados pelos fatores sejam considerados e observados em conjunto, tendo em vista contribuir para a melhoria da qualidade da auditoria.

Palavras-chave: julgamento e tomada de decisão em auditoria; confiança; pressão de tempo; complexidade da tarefa; heurística da ancoragem.

JEL Code: M42, D91, J81.

Editor-in-chief: Wesley Mendes-da-Silva (Fundação Getulio Vargas, EAESP, Brazil) (C) Reviewers: Ana Maria Roux Cesar (Universidade Presbiteriana Mackenzie, CCSA, Brazil) (1) Marcelo Cabus Klotzle (Pontifícia Universidade Católica do Rio de Janeiro, IAG, Brazil) (6) One of the reviewers chose not to disclose his/her identity. Peer Review Report: The Peer Review Report is available at this external URL. Received: February 07, 2020 Last version received: August 23, 2020 Accepted: August 26, 2020 


\section{INTRODUCTION}

The issuance of an independent auditor's opinion on the trust of the organizations' accounting information contributes to a business environment, characterized by reliability and credibility, essential for the smooth functioning of the capital and financial markets (Newman, Patterson, \& Smith, 2005; Ojo, 2008).

Greater attention needs to be paid to issues involving judgment and decision-making (JDM) in auditing, as professionalsalsodealwithanactivity that requiresimportant judgments and decision-making on a constant basis (Bonner, 1999; Grenier, Reffett, Simon, \& Warne, 2018). This is something important as it can affect the professional reputation and performance of auditors, as well as impacting other stakeholders, including coworkers, business owners, and the organization as a whole (Houston, Peters, \& Pratt, 1999; Mala \& Chand, 2015).

During the analysis of the JDM professionals, when observing the performance in the practical activity, or when using a simulation scenario, the adaptive choice of decision heuristics can often provide compensation for effort or reasonable precision (Payne, Bettman, \& Johnson, 1992; Tversky \& Kahneman, 1974). The ability to adapt real decision behavior to changes in decision tasks, contexts, and goals reveals that people sometimes adapt their behavior in ways that seem reasonable in view of the effort and precision of judgment and decisionmaking (Payne et al., 1992).

The use of heuristics has been observed in behavioral contexts, with discussions centered on practical situations of judges and decision-makers who face several situations, among which we can highlight the situations of professional risks and pressures of different natures (Bedard \& Wright, 1994; Cohen \& Avila, 2018). In this context, time pressure and task complexity are also considered, since the level of difficulty employed in the tasks involves pressure, which generates a greater number of uncertainties for making judgments and decisionmaking.

In order to improve the judgment and decisionmaking process, studies in this context have discussed various aspects of the audit and accounting literature, which has led to inquiries about the possibility of categorizing the elements discussed into personal, environmental, and task factors, but also have generated reflections on possible connections between these factors (Bonner, 1999; Mala \& Chand, 2015). Although the studies carried out on JDM are grouped into three major categories - personal, environmental, and task factors - , the interrelationship of these three perspectives is important and offers scope for new research (Mala \& Chand, 2015; Trotman, Bauer,
\& Humphreys, 2015). As some studies have shown that, in isolation, there are evidences of the influence of personal, environmental, and task factors in the judgment and decision-making in auditing, new studies may show the joint and interactive effect of these factors in the JDM, since it is not just one of them that exerts influence.

Trust (personal factor), time pressure (environmental factor), and complexity (task factor) are factors that have shown evidence of individual influence in judgment and decision-making in auditing. Time pressure, characterized as an environmental factor, makes the audit professional have to perform JDM quickly, which may result in forgetfulness or error of judgment and decision-making and, thus, impair the quality of the JDM (Bamber \& Bylinski, 1987; Gundry \& Liyanarachchi, 2007; Svanström, 2016). The complexity, as a task factor, being high also tends to increase the difficulty and uncertainty in the JDM in auditing, impairing the quality of the work (Alissa, Capkun, Jeanjean, \& Suca, 2014; Bonner, 1994; Tan \& Kao, 1999). Trust in the coworker, as a personal factor, is characterized as the belief that another person can perform actions that contribute to the first, such as minimizing uncertainty in the judgment and decision-making process when exchanging advice between colleagues from work (Anderson \& Narus, 1990). In view of a more consistent JDM, professionals seek to exchange advice with one or more trusted colleagues (Han, Jamal, \& Tan, 2011; Harvey \& Fischer, 1997; Kennedy, Kleinmuntz, \& Peecher, 1997).

As the engagement of more than one professional is common in auditing, the performance of team activities favors the observation of trust between some auditors. With the presence of trust among some professionals, it is observed that exchanged advice can minimize the effect that time pressure and complexity have on JDM (Kadous, Leiby, \& Peecher, 2013; Mayer, Davis, \& Schoorman, 1995). The lack of trust can intensify uncertainties and difficulties, increasing the influence of time pressure and complexity. In this context, we propose as a research question: what is the moderating effect of trust in the joint influence of time pressure and complexity in judgment and decision-making in audit? As a result of the research question, the objective arises to assess the moderating effect of trust (personal factor) in the joint influence of time pressure (environmental factor) and complexity (task factor) in the judgment and decision-making in audit.

Through an experimental approach, the study aims to contribute to the judgment and decision-making literature by showing the moderating effect of trust in the relationship of time pressure and complexity with the JDM. The study analyzes the quality of judgment and decision-making in auditing, represented by the joint 
and interactive assessment of the influence of personal, environmental, and task factors in the JDM - in this case, defining as factors (personal) trust, time pressure (environmental), and complexity (of task). The literature has a lack of studies that explore the three factors together and interactively, considering that it is not just one of them that influences the JDM. The direction, or the strength of a factor, analyzed in isolation, can be different when the joint influence is observed.

It is expected to show the joint and interactive effect of the factors under analysis, in which the negative effects that the pressure of time and complexity can generate are mitigated (moderated) by the personal factor trust. The main purpose of research in JDM in auditing is to understand individual and group judgments and decisions, since the entire audit process is permeated by professional judgments, evidenced by the common references to the need for judgments under International Auditing Standards (Trotman, Tan, \& Ang, 2011). Studies in this field have focused on the potential implications of policy improvements in areas such as the development and modification of audit methods, standards, and procedures, approaches to training and supervision, and the creation of forms of decision-making aid (Mala \& Chand, 2015).

The study is relevant, as it aims to contribute to improving the quality of the audit, by observing the individual characteristics of the auditor, the environment, and the task developed, which can help audit firms better understand the impacts of these factors on professional activities and, thus, plan and establish measurement criteria on the audit work conditions of its clients. Therefore, understanding how people make judgments and make decisions is important so that there is the possibility of proposing solutions to problems or implementing improvements in audit activities, which feed the entire financial market.

\section{THEORETICAL FRAMEWORK}

\section{Time pressure and complexity in judgment and decision-making}

The discussions on judging and decision-making (JDM) in accounting and auditing have, in general, the purpose of exploring points that reflect on the quality of judgment, seeking to describe the JDM process, as well as the factors that possibly impact in the audit process and the reasons for such impact. The focus is also on testing theories and highlighting the cognitive process of accountants, auditors, and users of accounting information (Trotman et al., 2011).
As the final decision-making comprises the definition of a course of action, to understand the JDM process it becomes necessary to take into account behavioral situations with a focus on understanding how personal factors (individual characteristics) affect choices (Hastie, 2001). In addition to personal, environmental and task factors are also related to the JDM and, therefore, need to be considered with a view to a better quality JDM.

Environmental factors are related to the conditions and circumstances that involve an individual while he performs a JDM task (Bonner, 1999). Environmental factors are considered to affect the auditor's JDM, changing his motivation and cognitive effort. As audit tasks are not performed in isolation, consideration of the task characteristics is followed by characteristics of the environment that surrounds the auditors and shapes the context in which the audit activities are carried out (Yankova, 2015). As an environmental factor, variables that relate to the conditions and circumstances that involve an individual while performing a JDM task, such as time restriction, are considered. Because it is more common in the area of accounting auditing, the term 'time constraint' is treated in this study as 'time pressure' (Bonner, 1999).

The environmental factor time pressure is common in audit activities, because even though professionals perform similar tasks at different times, the time allocated to the conclusions is not always the same, being, in most cases, below ideal (Bamber \& Bylinski, 1987; Svanström, 2016). According to Bamber and Bylinski (1987) and Svanström (2016), this type of scenario, especially with a high time pressure situation, can lead to a decrease in the quality of judgments and decision-making. When the auditor is under high pressure of time, he needs to identify ways to reduce the time to complete the work, as previously stipulated, which can lead to a decrease in audit steps and procedures, making him more susceptible to accept weak explanations (Svanström, 2016).

Task factors have elements that relate to the dimensions of the task, for example, its complexity. According to Yankova (2015), the processing of human information is dependent on structural characteristics of the task, as different tasks have different demands on a professional's cognitive resources, skills, knowledge, and effort, which impacts on the processing strategy of information used to perform the task. The task factor includes variables that relate to dimensions of the task.

The task complexity factor is also another element inherent in the auditor's activity. Characterized as the difficulty of executing an activity, the complexity varies between each task performed and such oscillation is related to the number of evidences and their consistencies, as well as to the type and size of the account balance 
(Chung \& Monroe, 2001). Campbell (1988) argues that, in situations of high complexity tasks, information can become poorly structured, present ambiguity, and be difficult to understand, especially in scenarios with inconsistent evidence. In this study, we adopt Bonner's (1994) arguments, which assess the complexity of the task, taking into account the amount of information, clarity, and accuracy of the information. The aforementioned author mentions that, in a situation of high complexity, the task contains a high amount of information, low clarity, and low accuracy of information. According to Libby and Lipe (1992) and Bonner (1994), the increased complexity of the task tends to impair the quality of the JDM.

Considering that the judgment and decision-making process in auditing involves personal, environmental, and task factors, the joint and interrelated analysis of these factors needs to be considered and explored, with a view to promoting improvements in the various judgments and decision-making (Bonner, 1999; Mala \& Chand, 2015; Trotman et al., 2015). According to Nelson and Tan (2005), as auditors do not work in isolation, it is crucial to understand how the people, tasks, and environment with which auditors interact influence their performance.

The trust factor in the relationship between time pressure and complexity with judgment and decision-making

Personal characteristics correspond to any distinguishable and lasting way in which an individual differs from others and exerts influence on a person's response to the environment and the task (Cohen \& Avila, 2018; Yankova, 2015). Personal characteristics reveal basic endogenous tendencies that include cognitive, motivational, and stylistic aspects, some of which are adaptive, but some of an effective nature (Yankova, 2015). The personal factor includes variables that are related to the characteristics that the judge and decision-maker presents in the task, such as knowledge, for example (Bonner, 1999).

In the JDM process, personal, environmental, and task factors can be decisive to affect the quality of the auditor's final work (Bonner, 1999; Mala \& Chand, 2015). Audit firms have encouraged consultation/exchange of advice with other coworkers to obtain a different point of view, hoping that this practice can generate a greater effort by the auditor to identify the best argument and thus reduce uncertainties and have greater conviction in the JDM (Kadous et al., 2013; KPMG, Glover, \& Prawitt, 2012).

Trust, treated as a personal factor, when present among coworkers, for example, tends to facilitate the exchange of professional advice. Thus, in the face of this situation of trust, the auditor tends to analyze the advice received with greater attention and depth, take it as a basis for greater consistency in his judgment and decisionmaking, and thus improve the quality of the activity performed (Kennedy et al., 1997). The literature shows that trust contributes to the reduction of uncertainty (Mayer et al., 1995). Consistent with this understanding, Kadous, Leiby and Peecher (2013) point out that the existence of stronger social ties can indicate an increase in the receptivity of the board, especially among audit teams, in which the exchange of advice is still perceived as unusual. As the auditing activity involves working in teams of professionals and judgments and decision-making belong to scenarios that have a high degree of uncertainty, the analysis of trust between coworkers becomes opportune.

Kadous et al. (2013) presented evidence of a 'trust/ anchoring' heuristics among auditors who received help from consultants and with whom they have a social bond. The argument put forward is that auditors often seek informal advice from colleagues to improve the quality of judgment, but the conditions under which the board improves the auditor's judgment are poorly understood. Auditors regularly request informal advice from other auditors, that is, information, recommendations, and alternative perspectives on their initial judgments, which serve as an anchor for judgment and final decision-making (Dalal \& Bonaccio, 2010; Kadous et al., 2013).

With the exchange of advice between trusted colleagues, the acceptability of this information ends up being greater and, thus, there is a greater tendency for the professional to anchor this advice to his JDM. With additional information, the JDM tends to be more consistent and contribute to the quality of the audit work. In situations where there is time pressure and complexity, uncertainties and difficulties increase for consistent processing and analysis of information on professional tasks, which can impair the quality of the JDM. When observing the factors trust (personal), time pressure (environmental), and complexity (task) in an interrelated way, trust tends to diminish the effect that time pressure and complexity generate in JDM. The same effect tends to be observed in the relationship between trust and complexity in the JDM. The pressure of time and complexity of the task can intensify doubts in the realization of the JDM. In the joint analysis, trust, by presenting anchoring elements, can moderate/mitigate the effect of doubts and uncertainties caused by the pressure of time and complexity of the task.

Given the above, it is observed that decisions are difficult whenever any type of uncertainty is present in the context of analysis (Payne et al., 1992; Tversky \& Kahneman, 1974). In JDM situations, people 
tend to put more effort into restructuring the information initially available, so that later on they can use a more accurate heuristic with a reasonable amount of effort. In this way, the adaptive use of heuristics can save substantial cognitive effort and, still, produce good solutions to decision problems (Payne et al., 1992).

Heuristics consist of general rules of influence that are used as a way to arrive at judgments and decisionmaking in tasks that involve uncertainties (Plous, 1993). Anchoring is one of the heuristics used in judgments and decision-making in scenarios of uncertainty. The anchoring heuristics show that, in many JDM situations, people make estimates starting from an initial value, that is, a parameter, in order to adjust and make the final choice, which can contribute to minimize the uncertainties (Tversky \& Kahneman, 1974).

Uncertainty can weaken the auditor's materiality argument, which can influence the distribution of probability around the true value of the proposal or materiality adjustment in audit (DeZoort, Hermanson, \& Houston, 2003). Thus, as uncertainty tends to influence the decrease in the chance of support for an adjustment and trust in the audit partner's advice tends to affect the reduction of uncertainty, it is expected that there will be greater support for making an audit/accounting adjustment when there is trust in the advice received. The accounting adjustment, in the experimental task, was treated in the context of a discussion of write-off of receivables, in which there was a disagreement between two auditors. The research participant, faced with the analyzed scenario, which also involved materiality, received advice from a coworker and was asked to decide whether to support the adjustment. Thus, we have the following hypothesis:

H1 - Higher level of trust increases the auditor's propensity to follow the advice received in support of accounting adjustment.

It is understood that the environmental factor time pressure influences the auditor's JDM. The quality of judgment and decision-making tends to be impaired in time pressure situations, in which the probability of increasing uncertainty and errors may be greater than in situations without this pressure (Bamber \& Bylinski, 1987; Gundry \& Liyanarachchi, 2007; Pierce \& Sweeney, 2004; Svanström, 2016).

Although auditors perform similar tasks at different times, it is common for time allocation to have a large discrepancy between these similar tasks. Svanström (2016) argues that, in audit activities where the time for completion is short, the quality of the JDM is at risk. In time pressure situations, the difficulty and uncertainty of the task tend to increase, which will negatively influence a possible belief in the correct value of an adjustment in materiality (DeZoort et al., 2003). DeZoort, Hermanson and Houston (2003) argue that, in such a scenario, the auditor will face more resistance to support an adjustment. Thus, we have the following hypothesis:

H2 - Time pressure decreases the auditor's propensity to make an accounting adjustment.

It is understood that the task complexity factor influences the auditor's JDM. According to Bonner (1994), the increase in the complexity levels of the task results in more information to be analyzed, with greater imprecision and uncertainty. In this situation, it is expected that the quality of the JDM will be negatively affected. When there is a lack of consensus among audit professionals, uncertainty intensifies, especially in highly difficult scenarios, which auditors may encounter when performing simultaneous JDMs for various audit tasks, with much information and procedures that can be adopted (Alissa et al., 2014; Libby \& Lipe, 1992; Mohd-Sanusi \& Mohd-Iskandar, 2006). Uncertainty and difficulty tend to vary during the tasks, mainly because the audit work contains scenarios that fluctuate a lot in terms of low and high complexity.

According to Chung and Monroe (2001), this oscillation of scenario, between low and high complexity, is justified in the variation between the type and size of the account balance or group of accounts and in the amount of evidence and consistencies linked to the information obtained. Kahneman (1973) considers that the complexity of the task is related to the amount of attention span or mental processing required for the individual to complete a task. When considering that the increased complexity of the audit task results in difficulty and uncertainty around the exact value of a possible adjustment, we have the hypothesis:

H3 - Higher level of complexity decreases the auditor's propensity to make an accounting adjustment.

The literature has pointed out evidence of differences in judgments and decision-making for different cognitive processes adopted (Grenier et al., 2018; Mala \& Chand, 2015; Trotman et al., 2015). According to the aforementioned authors, these differences in JDMs have been observed as an isolated result of the influence of personal, environmental, and task factors. Evidence of isolated factors gives evidence that a joint analysis is necessary; environmental variables, for example, can influence the amount of effort, motivation, and knowledge applied by the decision-maker, as well as impact on the demands of the tasks (Libby \& Luft, 1993; Mala \& Chand, 2015). 
As the evidence points out that it is not just a factor that influences, it is expected a joint effect of these factors on the JDM. In audit work, it is common for professionals to perform similar tasks, but with different deadlines for completion, which can influence the quality of the JDM, especially in a negative way, when time pressure is present (Bamber \& Bylinski, 1987; Yeo \& Neal, 2008). Taking into account that time pressure impairs the quality of the audit, the final work becomes even more affected when the task has a high level of complexity (Bonner, 1994; Yeo \& Neal, 2008).

Taking into account that time pressure impairs the quality of the audit, the final work becomes even more affected when the task has a high level of complexity (Mayer et al., 1995; Kadous et al., 2013). The opposite can also happen: the lack of trust in the advice received can increase uncertainty in decisions and, thus, intensify the effect of time pressure and task complexity. Therefore, it is understood that the time pressure and complexity factors, moderated by the level of trust, have an influence on the performance of the audit adjustment. Thus, we have the hypothesis:

H4 - Time pressure and task complexity, together, moderated by the level of trust, influence judgment and decision-making.

\section{METHODOLOGICAL PROCEDURES}

\section{Experiment participants}

The experiment was composed by 132 independent auditors from 14 audit firms, registered with the Securities and Exchange Commission, headquartered in the states of Mato Grosso do Sul, Paraná, Santa Catarina, and Rio Grande do Sul. The invitation was initially made by telephone, with subsequent sending of email with the letter of introduction and details of the research. After acceptance, the legal responsible for the audit firm signed the Request Form and Authorization for the Development of Research in loco, in the audit firm. On the date scheduled for the onsite application of the experiment, before the audit task was performed, each participant read and signed the Free and Informed Consent Form (ICF). Of the 132 participants, 6 were excluded from the analysis because they did not correctly fill out the research instrument. Therefore, the final sample was composed of 126 auditors.

\section{Research construct}

Table 1 presents the construct with the research variables and sub-variables and the way used to measure them, in addition to the references that support such variables.

Table 1. Research construct.

\begin{tabular}{|c|c|c|c|c|}
\hline Factors & Variables & Sub-variables & Metrics & Authors \\
\hline \multirow{3}{*}{ Personal factor } & \multirow{3}{*}{ Trust (TRU) } & Capacity (CAP) & $\begin{array}{l}\text { Affirmatives } 1 \text { to } 6 \text { - Mayer et al. } \\
\text { (1995) model. }\end{array}$ & \multirow{3}{*}{$\begin{array}{l}\text { Mayer, Davis and Schoorman } \\
\text { (1995); Kadous et al. (2013); } \\
\text { Nalda, Guillen e Pechuan (2016). }\end{array}$} \\
\hline & & Integrity (INT) & $\begin{array}{l}\text { Affirmatives } 7 \text { to } 11 \text { - Mayer et al. } \\
\text { (1995) model. }\end{array}$ & \\
\hline & & Benevolence (BEN) & $\begin{array}{l}\text { Affirmatives } 12 \text { to } 17 \text { - Mayer et al. } \\
\text { (1995) model. }\end{array}$ & \\
\hline $\begin{array}{l}\text { Environmental } \\
\text { factor }\end{array}$ & Time pressure (PT) & - & $\begin{array}{l}\text { No time pressure established; With } \\
\text { time pressure established. }\end{array}$ & $\begin{array}{l}\text { Bamber and Bylinski (1987); } \\
\text { Svanström (2016). }\end{array}$ \\
\hline Task factor & $\begin{array}{l}\text { Complexity } \\
\text { (COMP) }\end{array}$ & - & $\begin{array}{l}\text { Low complexity (low amount of } \\
\text { information and high clarity/accuracy } \\
\text { of information); High complexity } \\
\text { (high amount of information and low } \\
\text { clarity/precision of information). }\end{array}$ & $\begin{array}{l}\text { Bonner (1994); Chung and } \\
\text { Monroe (2001). }\end{array}$ \\
\hline $\begin{array}{l}\text { Judgment and } \\
\text { decision-making }\end{array}$ & $\begin{array}{l}\text { Judgment and } \\
\text { decision-making } \\
\text { (JDM) }\end{array}$ & - & $\begin{array}{l}\text { Adjustment support }- \text { Scale } \\
\text { (-5: definitely not adjusting } \ldots \\
\text { 5: definitely adjusting). }\end{array}$ & $\begin{array}{l}\text { DeZoort et al. (2003); DeZoort, } \\
\text { Harrison and Taylor (2006). }\end{array}$ \\
\hline
\end{tabular}

Note. Source: research data. 


\section{Experimental design}

The experiment setup included a $2 \times 2 \times 2$ factorial, which required the composition of eight groups for the experimental treatment. In this composition, the independent variables, trust, time pressure, and task complexity, were tested using the eight possible combinations, as follows:

Group 1 - High Level of Trust (HLT), High Complexity (HC), and With Time Pressure (WTM);

Group 2 - High Level of Trust (HLT), Low Complexity (LC), and With Time Pressure (WTP);

Group 3 - High Level of Trust (HLT), Low Complexity (LC), and No Pressure and Time (NPT);

Group 4 - High Level of Trust (HLT), High Complexity (HC), and No Pressure and Time (NPT);

Group 5 - Low Trust Level (LTL), High Complexity (HC), and With Time Pressure (WTP);

Group 6 - Low Trust Level (LTL), Low Complexity (LC), and With Time Pressure (WTP);

Group 7 - Low Trust Level (LTL), Low Complexity (LC), and No Pressure and Time (NPT);

Group 8 - Low Trust Level (LTL), High Complexity (HC), and No Pressure and Time (NPT).

In each audit firm, the participants were divided randomly and equally into each of the eight groups, according to a standardized experimental script. With randomized control in the distribution of the participants in the experimental groups, the dimension of the experimental design was defined as between-participants (inter-subjects), with the purpose of understanding differences in behavior between different groups of participants. In the definition of the design between-participants, each experimental group is exposed to only one experimental condition (one level of the independent variable) (Aguiar, 2017).

The researcher in standardized speech, with previously established text, including emphasizing the non-permission of communication between the applicants, guided the participants. In the development of the experiment, control measures were adopted for threats of internal validity (maturation, history, subject mortality, instrumentation, selection, statistical regression, treatment imitation, and resentful demoralization) and external (population validity, ecological validity, and temporal validity), mentioned by Smith (2003).

\section{Data collection instrument}

Participants responded to an audit task involving materiality in the write-off of receivables, adapted from Mayer et al. (1995), DeZoort et al. (2003), DeZoort et al. (2006) and Kadous et al. (2013). As the instrument of the experiment was adapted and validated in other international studies, it underwent reverse translation, adjustments, and pre-tests.

The task involved discussing receivables writeoff, in which there was a disagreement between two auditors. The research participant, faced with the analyzed scenario, decided whether to support the adjustment, on a scale between -5 to +5 , presenting his argument. After completing the task, the participant answered the 'postexperiment questionnaire,' in which he presented his perception of the factors analyzed and the identification of demographic data. The instrument for data collection contained two parts. The first, composed of nine blocks, had the experiment scenario, while the second part had the post-experiment questionnaire.

Before we fully validated the instrument, we carried out the procedure to establish the time pressure condition. We carried out a pilot study to determine the distribution (mean and standard deviation) of time required to complete the tasks. The participants of this stage of the test were 23 accounting sciences students, who were taking the Audit subject. Despite the fact that audit professionals live more with the pressure of time in the day-to-day activity and may feel less intensely the effect of this factor in relation to academics, those who are taking the accounting audit subject can also be considered qualified to submission to professional scenarios. According to Grenier, Reffett, Simon and Warne (2018), there are advantages to using university students in experiments, among which stands out the fact that students can be able participants and represent a more geographically diverse population.

In the procedure to establish the time pressure condition, after finding a normal distribution of times, we defined the first decile of times to establish the duration of low and high complexity tasks, in the time pressure condition. We defined the choice of the first decile as the condition of extreme time pressure. In this sense, through the first decile, we established that the low complexity task lasts 11 minutes and the high complexity task takes 13 minutes. In the variable time pressure (environmental factor), a group of participants performed the task with no time indication (without established time pressure), while another group had a determined time, considered as a high-pressure situation (with established time pressure). 
For the personal factor dimension, we chose the independent variable trust. In this condition of the experimental task, the participant was asked to think of an auditor, colleague or former coworker at the same hierarchical level and, subsequently, received advice from that professional. For this factor, two conditions were established. In the condition of a high level of trust, the group of participants received the advice of a professional they knew well and trusted professionally. The other group, with a low level of trust, received the advice of a professional they knew well and did not trust professionally.

To measure the level of trust, we used the model by Mayer et al. (1995), based on three factors: capacity, integrity, and benevolence. The use of the instrument by Mayer et al. (1995) aimed to indicate whether the level of trust of the indicated professional (who knew well and whom trusted professionally, or who did not trust professionally) corresponded to what was measured in the instrument. If the level of trust measured was different from the profile to be considered, the result of the participant was removed from the process of analysis of the experiment.

For the task factor dimension, the independent variable chosen was the task complexity. In the condition of complexity of the task, part of the participants performed the audit task, characterized as low complexity, and another part performed the task of high complexity. This factor is consistent with Bonner (1994) and Chung and Monroe (2001), in which the situation of low complexity contains low amount of information, high clarity, and high accuracy of information. In a highly complex situation, the task contains a high amount of information, low clarity, and low accuracy of information.

Before the application of the experiment, we carried out a pre-test of the complete instrument, with 186 accounting sciences students who were taking or completed the audit subject. The results of the pre-test analyzes presented in this topic allowed us to reveal that there is consistency in the instrument proposed for use with audit professionals. It is noteworthy that the research was applied after approval of the project by the Ethics Committee.

\section{Data analysis procedures}

For data analysis, we used descriptive statistics, the t-test, multiple linear regression, and the multiple correspondence analysis (ACM). In order to test the theoretical hypotheses $\mathrm{H} 1, \mathrm{H} 2$, and $\mathrm{H} 3$, regarding the observation that the factors trust, time pressure, and complexity individually influence JDM in auditing, we defined the t-test.

To test hypothesis H4, we defined multiple linear regression, using the ordinary least squares (OLS) model. To test hypothesis $\mathrm{H} 4$ - "Time pressure and task complexity, together, moderated by the level of trust, influence judgment and decision-making," we elaborated the following equation:

$$
J D M=\beta 0+\beta_{1} T P+\beta_{2} C O M P+\beta_{3} T R U+\beta_{4} T P^{*} C O M P+\beta_{5} T P^{*} C O M P^{*} T R U+\varepsilon i
$$

Where:

JDM = Judgment and decision-making, measured by the 11-point scale that ranged from - 5 (definitely not making the adjustment) to +5 (definitely making the adjustment);

$\mathrm{TP}=$ Time pressure, having the experimental treatment: without established time pressure and with established time pressure;

COMP = Task complexity, with experimental treatment: low complexity and high complexity;

TRU = Trust, having the experimental treatment: with a high level of trust and a low level of trust;

$\mathrm{TP}^{*} \mathrm{COMP}=$ Variable of interaction of task complexity and time pressure in judgment and decision-making;

$\mathrm{TP}^{*} \mathrm{COMP}{ }^{*} \mathrm{TRU}=$ Moderation variable between trust, task complexity, and time pressure in judgment and decisionmaking.

\section{RESULT AND DATA ANALYSIS}

\section{Descriptive analysis of variables}

Table 2 shows the auditors' judgment and decisionmaking (JDM), related to their professional characteristics.

It can be seen, through Table 2, that 66.6\% (84) of the auditors supported the proposed adjustment of the experimental case, $29.4 \%$ (37) did not support the adjustment, and 4\% (5) demonstrated uncertainty. The results show that the majority of participants indicated support for the proposed adjustment, with emphasis on those who opted for scale 4 (30.2\%) and 5 (19\%), with high conviction in judgment and decision-making. In relation to not supporting the proposed adjustment, the majority opted for the -5 scale $(17.5 \%)$, with high conviction in judgment and decision-making. 
Table 2. Judgment and decision-making in auditing.

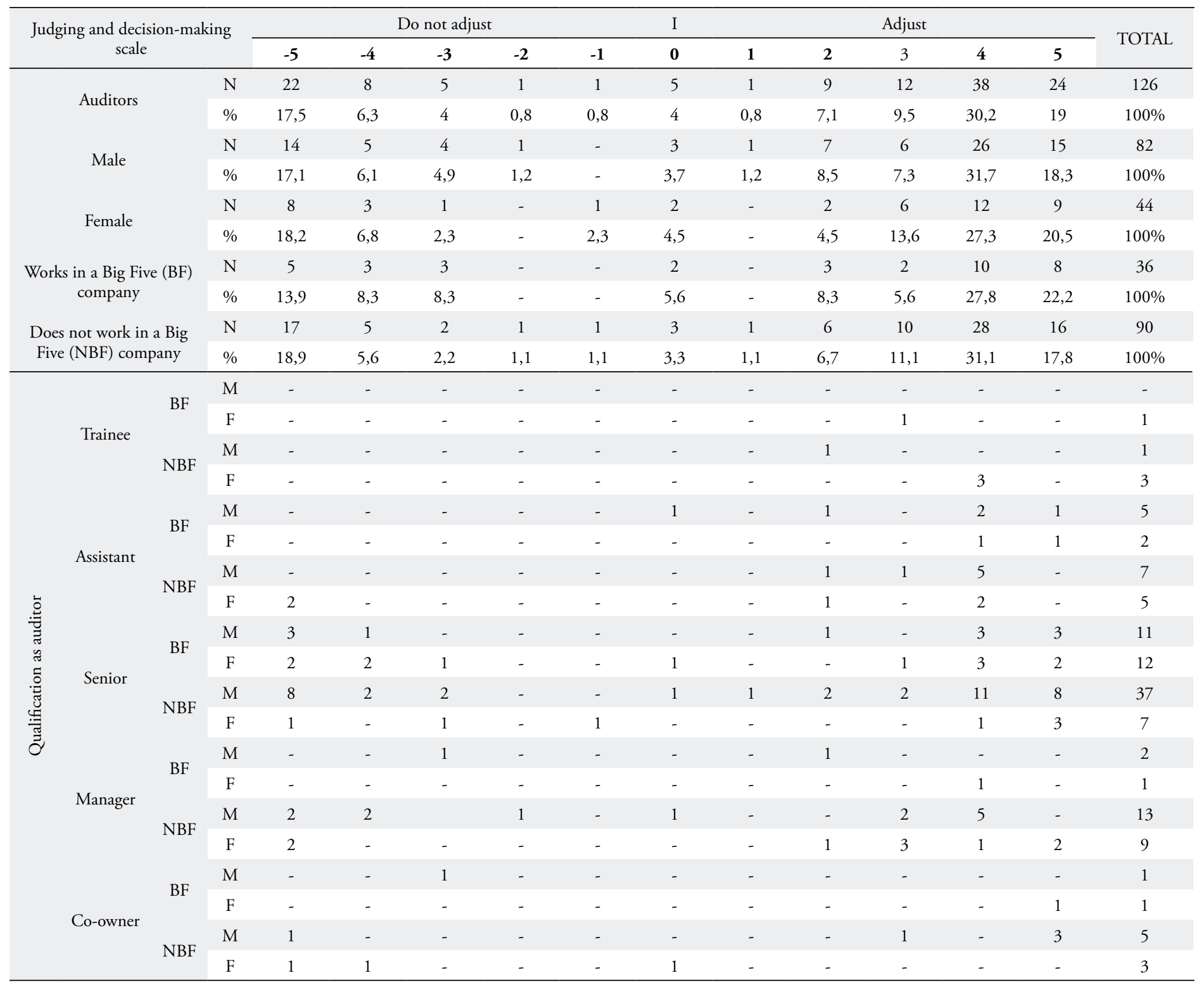

Note. $\mathrm{BF}=$ works in a Big Five company; $\mathrm{NBF}=$ does not work in a Big Five company; $\mathrm{U}=$ uncertain; $\mathrm{M}=$ male; $\mathrm{F}=$ female. Source: research data

In the analysis by sex, it is observed that the participants opted for the ends of the scales, revealing greater certainty in the judgment and decision-making performed. In the analysis of males, the predominance was on scale 4, with $31.7 \%$ (26) of the participants supporting the proposed adjustment. In females, although the percentage of predominance was lower, $27.3 \%$ (12), the predominance scale was the same as in males (scale 4).

Regarding the participants who supported the proposed adjustment, 23 (27.38\%) are auditors for Big Five firms and 61 (72.62\%) for non-Big Five firms. As for the non-support to the proposed adjustment and uncertain, 13
(30.95\%) are employees of Big Five firms and 29 (69.04\%) are employees of non-Big Five firms. In both situations, most participants were more firm in their positioning, opting for the end of the scale.

In the analysis of the JDM, at the levels of the auditor's qualification, size of the audit firm, and sex, the study revealed that the majority of the participants opted for supporting the proposed adjustment, except in the cases of partner of a Big Five firm and of partner of a firm not Big Five. Table 2 shows that the predominant position in the participation of the experiment was that of Senior, with 67 (53.17\%) participating auditors. 
Table 3 presents the descriptive statistics of the theoretical constructs analyzed in the experiment. On an 11-point scale, which ranged from - 5 (definitely not making the adjustment) to +5 (definitely making the adjustment), the judgment and decision-making of the participating auditors averaged 1.325 , with support for the adjustment, but close to 0 , which is the point of uncertainty. In this analysis, the median revealed a result of 3 and the standard deviation of 3.857.

In the analysis of the JDM by factor, it is observed in the trust variable that the average in the condition of high trust level was 3.641, indicating support for the proposed adjustment. This result shows an average close to the positive end, indicating conviction in supporting the adjustment. It is worth mentioning that this condition was the one with the lowest standard deviation, that is, it is the variable with the least measure of dispersion around the population average. In the condition of low trust level, the average was -1.065 , indicating non-support for adjustment. In addition to showing non-support for adjustment, the average was close to the point of uncertainty, which is zero.
In the experimental treatment of the environmental factor, in the condition without time pressure, the result shows that the JDM average was 2.230, with support for the proposed adjustment. In the condition with time pressure, the average was 0.477 , indicating uncertainty. The standard deviation was similar, 3.542 in the condition without time pressure and 3.973 in the condition with time pressure. These findings show that the auditor, in a situation that involves time pressure, will have difficulty in the complete and detailed analysis of the information and, thus, the tendency is to have greater uncertainty in his JDM.

In the third experimental treatment, task factor, in the condition of low complexity, the result presents an average of 2.127 in judgment and decision-making, which indicates support for the proposed adjustment. In the condition of high complexity, the experiment showed signs of uncertainty in the participant; the average was 0.524 . Under the conditions of this experimental treatment, the standard deviations show differences: in the low complexity one the standard deviation was 3.50 and in the high complexity one it was 4.047 .

Table 3. Descriptive statistics of theoretical construct.

\begin{tabular}{|c|c|c|c|c|c|c|c|c|}
\hline Factors/Variables & & Variables/Conditions & & Minimum & Maximum & Mean & Median & $\begin{array}{l}\text { Standard } \\
\text { deviation }\end{array}$ \\
\hline \multirow{7}{*}{$\begin{array}{l}\text { Judgment and } \\
\text { decision-making } \\
\text { factors (JDM) }\end{array}$} & \multirow{7}{*}{ JDM } & \multirow{2}{*}{ Trust (TRU) } & HTL & -3 & 5 & 3.641 & 4.000 & 1.577 \\
\hline & & & LTL & -5 & 5 & -1.065 & -3.000 & 4.060 \\
\hline & & \multirow{2}{*}{ Time pressure $(\mathrm{TP})$} & NTP & -5 & 5 & 2.230 & 4.000 & 3.542 \\
\hline & & & WTP & -5 & 5 & 0.477 & 2.000 & 3.973 \\
\hline & & \multirow{2}{*}{ Complexity (COMP) } & $\mathrm{LC}$ & -5 & 5 & 2.127 & 4.000 & 3.508 \\
\hline & & & $\mathrm{HC}$ & -5 & 5 & 0.524 & 2.000 & 4.047 \\
\hline & & JDM & & -5 & 5 & 1.325 & 3.000 & 3.857 \\
\hline
\end{tabular}

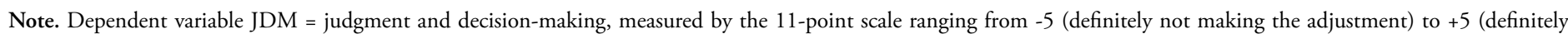

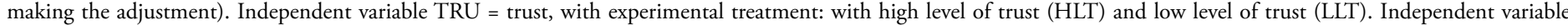

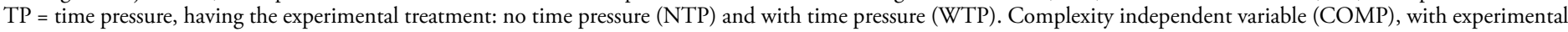
treatment: low complexity (LC) and high complexity (HC). Source: research data.

\section{Analysis of the result of the experiment}

In this section, we seek to verify the individual and joint effect of the factors trust, time pressure, and complexity in judgment and decision-making. To check the individual effect more consistently, we used the t-test, in order to identify whether the results of the groups of each experimental treatment show significant differences. To check the normality of the dependent variable, we used the Kolmogorov-Smirnov (KS) test.

In the KS test, the p-value (Sig.) of the factors trust, time pressure, and complexity are less than 0.05 , which at first accused the data not being normal. However, Hair, Black, Babin, Anderson and Tatham (2009) argue that "values that fall between -1 and +1 are still considered symmetrical" (Hair, Black, Babin, Anderson, \& Tatham, 2009 , p. 50). After checking the asymmetry of the factors trust $(-0.032)$, time pressure $(-0.746)$, and complexity $(0.000)$, it is possible to consider that the data under analysis has a normal distribution.

Table 4 shows the analysis of the t-test between the groups in the judgment and decision-making in the audit. 
Table 4. Analysis of the t-test of independent samples between groups in the JDM.

\begin{tabular}{|c|c|c|c|c|c|c|c|}
\hline \multicolumn{8}{|c|}{ Panel A - Personal factor trust } \\
\hline \multirow{2}{*}{$\begin{array}{l}\text { Judgment and decision- } \\
\text { making (JDM) }\end{array}$} & \multicolumn{2}{|c|}{$\begin{array}{l}\text { Levene's test for equality of } \\
\text { variances }\end{array}$} & \multicolumn{3}{|c|}{ t-test for equality of means } & \multicolumn{2}{|c|}{ Mean - Trust } \\
\hline & $\mathrm{F}$ & Sig. & $\mathrm{t}$ & $\mathrm{df}$ & Sig. & LTL & HTL \\
\hline Equal variances assumed & 136.950 & 0.000 & -8.624 & 124 & 0.000 & \multirow{2}{*}{-1.065} & \multirow{2}{*}{3.641} \\
\hline Equal variances not assumed & & & -8.524 & 78.513 & 0.000 & & \\
\hline
\end{tabular}

Panel B — Environmental factor time pressure

\begin{tabular}{|c|c|c|c|c|c|c|c|}
\hline \multirow{2}{*}{$\begin{array}{l}\text { Judgment and decision- } \\
\text { making (JDM) }\end{array}$} & \multicolumn{2}{|c|}{$\begin{array}{c}\text { Levene's test for equality of } \\
\text { variances }\end{array}$} & \multicolumn{3}{|c|}{$\mathrm{t}$-test for equality of means } & \multicolumn{2}{|c|}{ Mean — Time pressure } \\
\hline & $\mathrm{F}$ & Sig. & $\mathrm{t}$ & $\mathrm{df}$ & Sig. & NTP & WTP \\
\hline Equal variances assumed & 6.038 & 0.015 & 2.607 & 124 & 0.010 & \multirow{2}{*}{2.230} & \multirow{2}{*}{0.477} \\
\hline Equal variances not assumed & & & 2.617 & 123.68 & 0.010 & & \\
\hline
\end{tabular}

Panel C - Complexity task factor

\begin{tabular}{|c|c|c|c|c|c|c|c|}
\hline \multirow{2}{*}{$\begin{array}{l}\text { Judgment and decision- } \\
\text { making (JDM) }\end{array}$} & \multicolumn{2}{|c|}{$\begin{array}{c}\text { Levene's test for equality of } \\
\text { variances }\end{array}$} & \multicolumn{3}{|c|}{ t-test for equality of means } & \multicolumn{2}{|c|}{ Mean - Complexity } \\
\hline & $\mathrm{F}$ & Sig. & $\mathrm{t}$ & $\mathrm{df}$ & Sig. & $\mathrm{LC}$ & $\mathrm{HC}$ \\
\hline Equal variances assumed & 7.599 & 0.007 & 2.376 & 124 & 0.019 & \multirow{2}{*}{2.127} & \multirow{2}{*}{0.524} \\
\hline Equal variances not assumed & & & 2.376 & 121.546 & 0.019 & & \\
\hline
\end{tabular}

Note. JDM $=$ judgment and decision-making, measured by the 11-point scale that ranged from -5 (definitely not making the adjustment) to +5 (definitely making the adjustment). Panel A shows the t-test for the trust factor (TRU), having the experimental treatment: with high level of trust (HLT) and low trust level (LTL). Panel B shows the t-test for the time pressure (TP) factor, with the experimental treatment: no time pressure (NTP) and with time pressure (WTP). Panel C shows the t-test for the complexity factor, with the experimental treatment: low complexity (LC) and high complexity (HC). Source: research data.

In Levene's test of Panels A, B, and C, with $\mathrm{p}$-values less than 0.05 , it appears that the variances are not homogeneous and, in this sense, the test statistic to be used for the t-test is the one that does not assume equal variances. In the analysis of t-test, in Panel A - trust factor, as the p-value $=0.000$ (less than 0.05), H0 is rejected, which allows us to state that the average judgment and decision-making of the two groups (low trust and high trust) is significantly different.

Based on these findings, it is possible to infer that the advice obtained from a high-trust coworker supporting an audit adjustment tends to positively influence the proposed adjustment, which does not allow rejecting the hypothesis $\mathrm{H} 1$, that a higher level of trust increases the auditor's propensity to follow the advice received in support of accounting adjustment. This result corroborates Harvey and Fischer (1997), Kennedy, Kleinmuntz and Peecher (1997), Soll and Larrick (2009), DeZoort et al. (2003) and Kadous et al. (2013).

In Panel B - time pressure factor, as the $\mathrm{p}$-value $=0.010, \mathrm{H} 0$ is rejected, which allows us to affirm that the average judgment and decision-making of the two groups (no time pressure and with time pressure) is significantly many different.

In view of these findings, it is possible to infer that, under time pressure conditions, the auditor will not be able to analyze the entire proposed context in depth, and therefore tends to be undecided, not supporting the proposed adjustment, which corroborates Bamber and Bylinski (1987), DeZoort et al. (2003), Pierce and Sweeney (2004), Gundry and Liyanarachchi (2007) and Svanström (2016). According to the results found, it is not possible to reject hypothesis $\mathrm{H} 2$, that the pressure of time reduces the propensity of the auditor to make the accounting adjustment.

In Panel C - complexity factor, as p-value $=0.019$, $\mathrm{HO}$ is rejected, which allows us to state that the average judgment and decision-making of the two groups (low complexity and high complexity) is significantly different.

This finding reveals that, in situations of high complexity, which present situations of imprecision in information, as well as a high amount of information, people tend to be undecided, which corroborates the arguments of Kahneman (1973), Libby and Lipe (1992), 
Bonner (1994), Chung and Monroe (2001), Mohd-Sanusi and Mohd-Iskandar (2006) and Alissa, Capkun, Jeanjean and Suca (2014). In view of this observation, it is not allowed to reject hypothesis $\mathrm{H} 3$, that a higher level of complexity reduces the auditor's propensity to make the accounting adjustment.

After verifying the individual effect of the factors, the purpose is to assess the joint influence of the factors, through the moderating effect of trust in the joint influence of time pressure and complexity in the JDM. For that, we used multiple linear regression, model ordinary least squares (OLS), as shown in Table 5. Initially, we analyzed the normality and homoscedasticity of the residues.

The non-parametric KS test showed a significance of 0.044, which initially does not show evidence of a normal distribution of variables at a level of 5\%. Greene (2012) argues that, despite having normally distributed random errors, normality is not widely necessary to achieve much of the results of multiple regression, so this assumption can be mitigated.

In this context, Hair et al. (2009) argue that "values that fall between -1 and +1 are still considered symmetrical" (Hair et al., 2009, p. 50). After checking the asymmetry $(-0.231)$, it is considered that the residuals of the data under analysis have normal distribution.

In addition to the above, Levene's homoscedasticity test was applied, which revealed a significance of 0.909 , confirming the hypothesis that the error variance is uniform and that the residues are homoscedastic.

Then, Table 5 presents the results of the effect of moderation of trust in the joint influence of time pressure and complexity in the JDM.

Table 5. Multiple regression models for the influence of time pressure and complexity factors in the judgment and decision-making in auditing moderated by the trust factor.

\begin{tabular}{|c|c|c|c|c|c|c|c|}
\hline \multirow{2}{*}{\multicolumn{2}{|c|}{ Independent variables }} & \multicolumn{3}{|c|}{ Model $1-$ multiple linear regression without moderation } & \multicolumn{3}{|c|}{ Model 2 - multiple linear regression in moderation } \\
\hline & & \multicolumn{2}{|c|}{ Coefficient/Sig. } & VIF & \multicolumn{2}{|c|}{ Coefficient/Sig. } & VIF \\
\hline \multirow{2}{*}{\multicolumn{2}{|c|}{ Constant }} & Coefficient & 1.313 & \multirow{2}{*}{-} & Coefficient & 1.297 & \multirow{2}{*}{-} \\
\hline & & Sig. & 0.000 & & Sig. & 0.000 & \\
\hline \multirow{2}{*}{ Trust } & & Coefficient & 2.327 & \multirow{2}{*}{1.001} & Coefficient & 2.343 & \multirow{2}{*}{1.002} \\
\hline & & Sig. & 0.000 & & Sig. & 0.000 & \\
\hline \multirow{2}{*}{ ТP } & & Coefficient & -0.789 & \multirow{2}{*}{1.001} & Coefficient & -0.787 & \multirow{2}{*}{1.001} \\
\hline & & Sig. & 0.003 & & Sig. & 0.002 & \\
\hline \multirow{2}{*}{\multicolumn{2}{|c|}{ COMP }} & Coefficient & -0.789 & \multirow{2}{*}{1.000} & Coefficient & -0.821 & \multirow{2}{*}{1.002} \\
\hline & & Sig. & 0.002 & & Sig. & 0.001 & \\
\hline \multirow{2}{*}{\multicolumn{2}{|c|}{ TP*COMP }} & & & & Coefficient & 0.518 & \multirow{2}{*}{1.002} \\
\hline & & & & & Sig. & 0.040 & \\
\hline \multirow{2}{*}{\multicolumn{2}{|c|}{ TP*COMP*TRU }} & & & & Coefficient & -0.472 & \multirow{2}{*}{1.002} \\
\hline & & & & & Sig. & 0.062 & \\
\hline $\mathrm{R}$ & & & 0.679 & & & 0.702 & \\
\hline $\mathrm{R}^{2}$ & & & 0.460 & & & 0.493 & \\
\hline $\mathrm{R}^{2}$ adjusted & & & 0.447 & & & 0.472 & \\
\hline Durbin-Watson & & & 2.194 & & & 2.058 & \\
\hline \multirow{2}{*}{ Anova } & $\mathrm{F}$ & & 34.708 & & & 23.348 & \\
\hline & Sig. & & 0.000 & & & 0.000 & \\
\hline
\end{tabular}

a. Dependent variable: JDM.

b. Predictors - Model 1: (Constant), COMP, TRU, PT.

b. Predictors - Model 2: (Constant), TP*COMP*TRU, PT*COMP, TP, COMP, TRU.

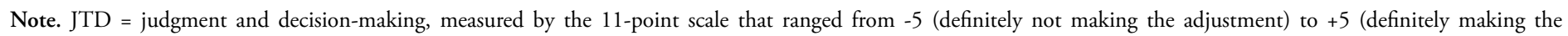

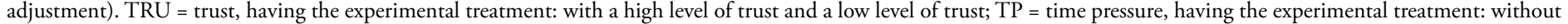

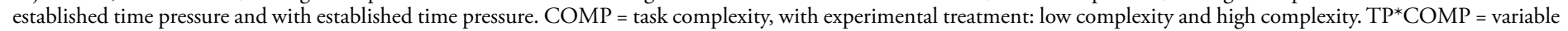

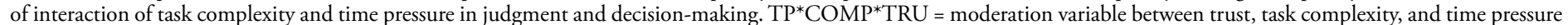

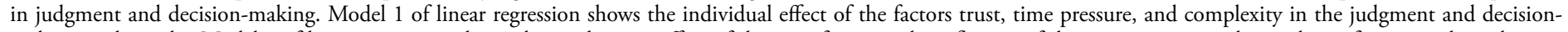

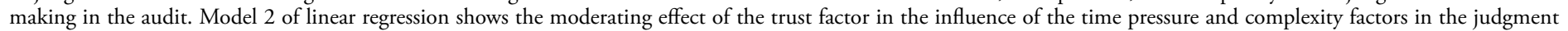
and decision-making in the audit. Source: research data. 
The regression Model 2, which analyzes the moderating effect, has an $\mathrm{R} 2$ of 0.493 , showing that the independent variables are responsible for $49.3 \%$ of the variation in judgment and decision-making in accounting auditing. Table 5 shows that the adjusted R2 of the JDM in Model 2 audit is good and close to the R2, which reveals a satisfactory explanatory power. When comparing the R2 of Model 2 with Model 1, it is observed that there is an increase in explanatory power through the insertion of moderation, from $46 \%$ to $49.3 \%$.

In the analysis of Durbin-Watson, Table 5 presents a value in range 2 for both models, which suggests the independence of the residues, indicating that there is no relationship between them. Table 5 also presents the analysis of variance of the variables in the regression models, which suggests the linearity in the data and that at least one of the explanatory variables included is significant to explain the behavior of the dependent variable.

In the analysis of VIF, the result of Model 2 confirms that there are no multicollinearity problems, since the values are not greater than 10 (Kennedy, 1998). According to Model 2, the independent variables trust (TRU), time pressure (TP), complexity (COMP), and influence of trust and time pressure (TP*TRU) can be considered statistically significant at the level of $5 \%$ (p-value $<0.05$ ) and trust moderates the joint influence of time pressure and complexity (PT*COMP*TRU), and can be considered statistically significant at the level of $10 \%$ (p-value $<0.10)$.

When comparing regression Model 2 with 1 , it is observed that the coefficients of the factors trust (TRU) and task complexity (COMP) increased and the time pressure factor (TP) had a small reduction. Although the coefficients of the trust, time pressure, and complexity factors have undergone minor changes, the results show that the trust factor continues to influence the auditor in supporting the proposed adjustment, and the time pressure and the task complexity factors still influence the non-support to the adjustment proposed.

In the analysis of the influence of complexity and time pressure (COMP*TP) in judgment and decisionmaking, although the coefficient is positive, the influence remains negative, as the individual signs of the time pressure and complexity factors are negative. What is observed in this interaction is that, because the negative time pressure coefficient is less than the complexity, the negative influence is attenuated. This result shows that the time pressure factor and complexity remain influencing the auditor to not support the proposed adjustment.

In the analysis of the moderating effect (COMP*TP*TRU), the study showed that the personal trust factor moderates significantly and negatively the influence of the environmental factor time pressure and the task factor complexity in the judgment and decisionmaking in audit. Despite the moderation of trust being negative, when compared to the influence of complexity and time pressure on JDM without moderation, the result shows that moderation mitigates the effect of complexity and time pressure. This finding is consistent with the arguments of Bamber and Bylinski (1987), Bonner (1994), Mayer et al. (1995), Chung and Monroe (2001) and Kadous et al. (2013). Thus, the hypothesis H4 (that the pressure of time and the complexity of the task, together, moderated by the level of trust, influence judgment and decision-making) is not rejected. It is understood that there is support for the acceptance of $\mathrm{H} 4$, although this relationship has been attenuated with a significance of $10 \%$.

In order to show greater consistency in the research instrument and in the findings, after the application of the experimental treatments, the post-experiment questionnaire verified the participants' perception regarding the treatments to which they were submitted. Was performed the analysis using perceptual maps from the multiple correspondence analysis. As a test of consistency of the instrument, the effects of the experimental treatments of personal, environmental, and task factors were felt by the participants, which revealed consistency in the observed factors.

\section{CONCLUSION AND RECOMMENDATIONS}

The present study carried out an experiment with 126 independent auditors, in order to assess the moderating effect of trust in the joint influence of time pressure and complexity in the judgment and decision-making in auditing. In the factor analysis, one of the findings showed that a higher level of trust increases the auditor's propensity to follow the advice received in support of the accounting adjustment. We found that the advice from someone of high trust, indicating support for the proposed adjustment, reflects positively on the final decision. With this, it is possible to infer that the personal trust factor influences the auditor's JDM.

When professionals from the audit firm receive advice, information from other points of view is being analyzed. In the existence of advice received to proceed with the interpretation of the context and realization of the final JDM, it is possible to perceive the use of the anchoring heuristic, as the individual lives with professional scenarios that, every day, present a different situation, with clients from different areas and sizes, which can generate uncertainties and difficulties in completing the stipulated tasks. Thus, in the face of JDM under uncertainty, professionals tend to adjust their final decision based on initial information or value, which can be treated as an anchor. The tendency 
for the advice received to be treated as an anchor will occur mainly when it comes from someone with high trust.

The experiment also revealed that time pressure decreases the auditor's propensity to perform the accounting adjustment, which allows to infer that the environmental factor time pressure influences JDM. Another finding showed that a higher level of complexity decreases the auditor's propensity to perform the accounting adjustment, which indicates that the complexity task factor influences the JDM.

The experiment applied to the auditors allowed us to understand that the time pressure and the complexity of the task, together, moderated by the level of trust, influence judgment and decision-making. The experiment showed that trust negatively moderates the joint influence of time pressure and complexity on JDM. It was observed that the time pressure and the task complexity negatively influence the JDM, but by including trust as a moderating factor, although the result remains negative, indicating no support for the proposed adjustment, the effect of time pressure and complexity is mitigated, reducing the auditor's difficulties and uncertainties in the JDM.

As the auditor deals with several tasks in a short period, under pressure of time and with high levels of difficulty, it becomes necessary to identify ways in which situations of pressure and high complexity do not decrease the quality of the work. One of the ways used by professionals is heuristics, in which there is the facilitation and simplification of mental processes in the analysis and selection of information for the JDM. There is also evidence that heuristics reduce time and effort in JDM, which mitigates the negative effect that timeconsuming and highly complex tasks require. Tasks that have high complexity demand more time to be completed, therefore, the time to be allocated needs to be planned in order not to become another factor that can negatively affect activities. Teams formed by highly trustworthy auditors can be important in situations of high complexity, advice can be exchanged more frequently and, thus, as an anchoring heuristic (in this case, the trust that a person has in the colleague who gives advice), they can serve as initial parameters and be more easily evaluated and absorbed.
The research advances by revealing that the influence of personal, environmental, and task factors, in the judgment and decision-making in auditing, occurs in an interrelated and joint way through the effect of trust in the relationship of time pressure and complexity with the JDM. Thus, it is essential to understand these factors as a whole, with a view to promoting improvements in the JDM process. The research corroborated the evidence and arguments presented by Bonner (1999), Mala and Chand (2015) and Trotman, Bauer and Humphreys (2015), confirming the connections between the factors. As the findings of previous studies have shown, in isolation, evidence of the influence of personal, environmental, and task aspects in the JDM in auditing, it was possible to show the joint and interactive effect of these factors in the JDM, since it is not just one that exercises influence.

These findings are consistent with those found in the pre-test with accountancy academics who have attended or were attending the audit discipline. The pre-test performed validated the instrument, confirming the robustness of the proposed experimental treatments.

The experiment as an operationalization method allowed the identification and control of threats to internal and external validities, eliminating the influence of strange variables and ambiguity in the interpretation of results. In this method, the participant's JDM was observed by the researcher, with no possibility for the participants to evaluate their own performance, in which they could be overconfident and overestimate their performance. The consistency of the experiment was reinforced with the postexperiment questionnaire, in which the participants felt the effects of the experimental treatments of the trust, time pressure, and complexity factors.

For future research, we suggest that atypical periods be considered, as the closing period of the audit report, in which professionals have a high volume of activities. It is also suggested that further studies increase the sample, for an analysis that takes into account in the experimental treatments some control variables, such as sex, experience, and size of the audit firm. In the present research, this demographic and characteristic information of the audit firm was captured and analyzed, but not treated as experimental groups. 


\section{REFERENCES}

Aguiar, A. B. (2017). Pesquisa experimental em contabilidade: Propósito, desenho e execução. Advances in Scientific and Applied Accounting, 10(2), 224-244. https://doi.org/10.14392/ASAA.2017100206

Alissa, W., Capkun, V., Jeanjean, T., \& Suca, N. (2014). An empirical investigation of the impact of audit and auditor characteristics on auditor performance. Accounting, Organizations and Society, 39(7), 495-510. https://doi.org/10.1016/j.aos.2014.06.003

Anderson, J. C., \& Narus, J. A. (1990). A model of distributor firm and manufacturer firm working partnerships. Journal of Marketing, 54(1), 42-58. Retrieved from https://www.jstor.org/stable/1252172?.seq =1

Bamber, E. M., \& Bylinski, J. H. (1987). The effects of the planning memorandum, time pressure and individual auditor characteristics on audit managers' review time judgments. Contemporary Accounting Research, 4(1), 127-143. https://doi.org/10.1111/j.1911-3846.1987.tb00659.x

Bedard, J. C., \& Wright, A. M. (1994). The functionality of decision heuristics: Reliance on prior audit adjustments in evidential planning. Behavioral Research in Accounting, 6(Supplement), 62-89.

Bonner, S. E. (1994). A model of the effects of audit task complexity. Accounting, Organizations and Society, 19(3), 213-234. https://doi.org/10.1016/0361-3682(94)90033-7

Bonner, S. E. (1999). Judgment and decision-making research in accounting. Accounting Horizons, 13(4), 385-398. Retrieved from https://www.marshall.usc.edu/sites/ default/files/sbonner/intellcont/BonnerJDM1999-1.pdf

Campbell, D. J. (1988). Task complexity: A review and analysis. Academy of Management Review, 13(1), 40-52. https://doi.org/10.5465/AMR.1988.4306775

Chung, J., \& Monroe, G. S. (2001). A research note on the effects of gender and task complexity on an audit judgment. Behavioral Research in Accounting, 13(1), 111-125. https://doi.org/10.2308/bria.2001.13.1.111

Cohen, M., \& Avila, M. G. (2018). O excesso de correspondência: um experimento com auditores no contexto brasileiro. Contabilidade Vista \& Revista, 29(2), 1-17. https://doi.org/10.22561/cvr.v29i2.3063

Dalal, R. S., \& Bonaccio, S. (2010). What types of advice do decision-makers prefer? Organizational Behavior and Human Decision Processes, 112(1), 11-23. https://doi.org/10.1016/j.obhdp.2009.11.007

DeZoort, F. T., Hermanson, D. R., \& Houston, R. W. (2003). Audit committee support for auditors: The effects of materiality justification and accounting precision. Journal of Accounting and Public Policy, 22(2), 175-199. https://doi.org/10.1016/S0278-4254(03)00007-3

DeZoort, T., Harrison, P., \& Taylor, M. (2006). Accountability and auditors' materiality judgments: The effects of differential pressure strength on conservatism, variability, and effort. Accounting, Organizations and Society, 31(4-5), 373-390. https://doi.org/10.1016/j.aos.2005.09.001
Greene, W. H. (2012). Econometric analysis (7th ed). New Jersey: Prentice Hall.

Grenier, J. H., Reffett, A., Simon, C. A., \& Warne, R. C. (2018). Researching juror judgment and decision making in cases of alleged auditor negligence: A toolkit for new scholars. Behavioral Research in Accounting, 30(1), 99-110. https://doi.org/10.2308/bria-51878

Gundry, L. C., \& Liyanarachchi, G. A. (2007). Time budget pressure, auditors' personality type, and the incidence of reduced audit quality practices. Pacific Accounting Review, 19(2), 125-152. https://doi.org/10.1108/01140580710819898

Hair, J. F. Jr., Black, W. C., Babin, B. J., Anderson, R.E., \& Tatham, R.L. (2009). Análise multivariada de dados (6th ed). Porto Alegre: Bookman.

Han, J., Jamal, K., \& Tan, H. T. (2011). Auditors' overconfidence in predicting the technical knowledge of superiors and subordinates. Auditing: AJournalof Practice \& Theory, 30(1), 101-119. https://doi.org/10.2308/aud.2011.30.1.101

Harvey, N., \& Fischer, I. (1997). Taking advice: Accepting help, improving judgment, and sharing responsibility. Organizational Behavior and Human Decision Processes, 70(2), 117-133. https://doi.org/10.1006/obhd.1997.2697

Hastie, R. (2001). Problems for judgment and decision making. Review of Psychology, 52(1), 653-683. https://doi.org/10.1146/annurev.psych.52.1.653

Houston, R. W., Peters, M. F., \& Pratt, J. H. (1999). The audit risk model, business risk and audit-planning decisions. The Accounting Review, 74(3), 281-298. Retrieved from https://www.jstor.org/stable/248489?seq=1

Kadous, K., Leiby, J., \& Peecher, M. E. (2013). How do auditors weight informal contrary advice? The joint influence of advisor social bond and advice justifiability. The Accounting Review, 88(6), 2061-2087. https://doi.org/10.2308/accr-50529

Kahneman, D. (1973). Attention and effort. Englewood Cliffs, NJ: Prentice-Hall.

Kennedy, J., Kleinmuntz, D. N., \& Peecher, M. E. (1997). Determinants of the justifiability of performance in ill-structured audit tasks. Journal of Accounting Research, 35, 105-123. Retrieved from https://www.jstor.org/stable/2491456? ?seq=1

Kennedy, P. (1998). A guide to econometrics (4th ed). Oxford: MIT Press.

KPMG, Glover, S. M., \& Prawitt, D. F. (2012). Enhancing board oversight: Avoiding judgment traps and biases. New York, NY: COSO.

Libby, R., \& Lipe, M. (1992). Incentive effects and the cognitive processes involved in accounting judgments. Journal of Accounting Research, 30(2), 249-273. Retrieved from https://www.jstor.org/stable/2491126?seq=1 
Libby, R., \& Luft, J. (1993). Determinants of judgment performance in accounting settings: Ability, knowledge, motivation, and environment. Accounting, Organizations and Society, 18(5), 425-450. https://doi.org/10.1016/0361-3682(93)90040-D

Mala, R., \& Chand, P. (2015). Judgment and decision-making research in auditing and accounting: future research implications of person, task, and environment perspective. Accounting Perspectives, 14(1), 1-50. https://doi.org/10.1111/1911-3838.12040

Mayer, R. C., Davis, J. H., \& Schoorman, F. D. (1995). An integrative model of organizational trust. Academy of Management Review, 20(3), 709-734. https://doi.org/10.2307/258792

Mohd-Sanusi, Z., \& Mohd-Iskandar, T. (2006). Audit judgment performance: Assessing the effect of performance incentives, effort and task complexity. Managerial Auditing Journal, 22(1), 34-52. https://doi.org/10.1108/02686900710715639

Nalda, A. L., Guillen, M., \& Pechuan, I. G. (2016). The influence of ability, benevolence, and integrity in trust between managers and subordinates: The role of ethical reasoning. Business Ethics: A European Review, 25(4), 556-576. https://doi.org/10.1111/beer.12117

Nelson, M., \& Tan, H. T. (2005). Judgment and decision making research in auditing: A task, person, and interpersonal interaction perspective. Auditing: A Journal of Practice o Theory, 24(s-1), 41-71. https://doi.org/10.2308/aud.2005.24.s-1.41

Newman, D. P., Patterson, E. R., \& Smith, J. R. (2005). The role of auditing in investor protection. The Accounting Review, 80(1), 289-313. Retrieved from https://www.jstor.org/stable/4093170?seq=1

Ojo, M. (2008). The role of the external auditor in the regulation and supervision of the UK banking system. Journal of Corporate Ownership and Control, 5(4), 1-20. Retrieved from https://papers.ssrn.com/sol3/papers.cfm?abstract $\underline{\mathrm{id}=1408612}$

Payne, J. W., Bettman, J. R., \& Johnson, E. J. (1992). Behavioral decision research: A constructive processing perspective. Annual Review of Psychology, 43(1), 87-131. https://doi.org/10.1146/annurev.ps.43.020192.000511
Pierce, B., \& Sweeney, B. (2004). Cost-quality conflict in audit firms: An empirical investigation. European Accounting Review, 13(3), 415-441. https://doi.org/10.1080/0963818042000216794

Plous, S. (1993). The Psychology of judgment and decision-making. New York: Mcgraw-Hill Book Company.

Smith, M. (2003). Research methods in accounting. London: Sage.

Soll, J. B., \& Larrick, R. P. (2009). Strategies for revising judgment: How (and how well) people use others' opinions. Journal of Experimental Psychology: Learning, Memory, and Cognition, 35(3), 780-805. https://doi.org/10.1037/a0015145

Svanström, T. (2016). Time pressure, training activities and dysfunctional auditor behaviour: evidence from small audit firms. International Journal of Auditing, 20(1), 4251. https://doi.org/10.1111/ijau.12054

Tan, H.T, \& Kao, A (1999). Accountability effects on auditors' performance: The influence of knowledge, problemsolving ability, and task complexity. Accounting Research, 37(1), 209-223. https://doi.org/10.2307/2491404

Trotman, K. T., Tan, H. C., \& Ang, N. (2011). Fifty-year overview of judgment and decision-making research in accounting. Accounting \& Finance, 51(1), 278-360. https://doi.org/10.1111/j.1467-629X.2010.00398.x

Trotman, K. T., Bauer, T. D., \& Humphreys, K. A. (2015). Group judgment and decision making in auditing: Past and future research. Accounting, Organizations and Society, 47, 56-72. https://doi.org/10.1016/j.aos.2015.09.004

Tversky, A., \& Kahneman, D. (1974). Judgment under uncertainty: Heuristics and biases. Science, 185(4157), 1124-1131. https://doi.org/10.1126/science.185.4157.1124

Yankova, K. (2015). The influence of information order effects and trait professional skepticism on auditors' belief revisions: A Theoretical and empirical analysis. Auditing and Accounting Studies. Duisburg: Springer.

Yeo, G., \& Neal, A. (2008). Subjective cognitive effort: A model of states, traits, and time. Journal of Applied Psychology, 93(3), 617-631. https://doi.org/10.1037/0021-9010.93.3.617 


\section{Authorship}

\section{Cleston Alexandre dos Santos*}

Universidade Federal de Mato Grosso do Sul, Programa de PósGraduação em Ciências Contábeis

Av. Sen. Filinto Müler, no 1555, Cidade Universitária, 79046-460, Campo Grande, MS, Brazil

E-mail address: cleston.alexandre@ufms.br

(1) https://orcid.org/0000-0001-7014-6644

\section{Paulo Roberto da Cunha}

Universidade Regional de Blumenau, Programa de Pós-Graduação em Ciências Contábeis

Rua Antonio da Veiga, no 140, Sala D202 - PPGCC, Bairro Victor Konder, 89030-903, Blumenau, SC, Brazil

Universidade do Estado de Santa Catarina, Curso de Graduação em Ciências Contábeis

Rua Dr. Getúlio Vargas, no 2822, Bela Vista, 89.140-000, Ibirama, SC, Brazil

E-mail address: pauloccsa@furb.br

(1) https://orcid.org/0000-0001-5805-9329

* Corresponding Author

\section{Funding}

The authors thank the Conselho Nacional de Desenvolvimento Científico e Tecnológico - CNPQ, process \#423588/2018-4, for the financial support granted.

\section{Conflict of Interests}

The authors have stated that there is no conflict of interest.

\section{Copyrights}

RAC owns the copyright to this content.

\section{Plagiarism Check}

The RAC maintains the practice of submitting all documents approved for publication to the plagiarism check, using specific tools, e.g.: iThenticate.

\section{Authors' Contributions}

$1^{\text {st }}$ author: conceptualization (equal); data curation (equal); formal analysis (equal); investigation (equal); methodology (equal); project administration (equal); resources (equal); software (equal); supervision (equal); validation (equal); visualization (equal); writing-original draft (equal); writingreview \& editing (equal).

$2^{\text {nd }}$ author: conceptualization (equal); data curation (equal); formal analysis (equal); investigation (equal); methodology (equal); project administration (equal); resources (equal); software (equal); supervision (equal); validation (equal); visualization (equal); writing-original draft (equal); writingreview $\&$ editing (equal).

\section{Peer Review Method}

This content was evaluated using the double-blind peer review process. The disclosure of the reviewers' information on the first page, as well as the Peer Review Report, is made only after concluding the evaluation process, and with the voluntary consent of the respective reviewers and authors.

\section{Data Availability}

The authors chose not to share their database, and claim that they do so in view of the fact that, according to the Free and Informed Consent Term (TCLE), written and signed by the research participants, it states that under no circumstances will the data generated by the research gain publicity. The same document states that the results, presented in aggregate form, could be disseminated for the purpose of academic work. Thus, following the document approved by the Ethics Committee (CAAE 71147517.5.0000.5370) by the respective institution in which the research was conducted, it is understood by the non-disclosure of data. Also, the authors claim that the data used in this article is unpublished.

RAC encourages data sharing but, in compliance with ethical principles, it does not demand the disclosure of any means of identifying research subjects, preserving the privacy of research subjects. The practice of open data is to enable the reproducibility of results, and to ensure the unrestricted transparency of the results of the published research, without requiring the identity of research subjects. 